\title{
Mechanical Property of SnSe Single Crystal Prepared via Vertical Bridgman Method
}

\author{
JIN Min ${ }^{1}$, BAI Xudong ${ }^{1,2}$, ZHAO Su$^{1}$, ZHANG Rulin ${ }^{1}$, CHEN Yuqi ${ }^{1}$, ZHOU Lina ${ }^{1}$
}

(1. College of Materials, Shanghai Dianji University, Shanghai 201306, China; 2. School of Materials Science and Engineering, University of Shanghai for Science and Technology, Shanghai 200093, China)

\begin{abstract}
IV-VI SnSe single crystal is an attractive thermoelectric (TE) material due to its outstanding TE behavior and environment friendly charactistic. In this work, an effective way for SnSe single crystal growth was explored, and the mechanical property of the as-prepared product was investigated. Undoped SnSe single crystal with accurate stoichiometric ratio was successfully grown via a vertical Bridgman method. The as-grown SnSe single crystal has standard orthorhombic Pnma space group at room temperature. It is easy to cleave along (100) plane because of its weak link between adjacent Sn-Se layers. Microindentation test reveals that SnSe single crystal is a very soft material as its average Vickers microhardness $\mathrm{HV}$ is only $53 \mathrm{MPa}$ under 0.01-0.05 kg applied loads. However, it displays excellent fracture toughness due to strong heteropolar bonds between Sn and Se atoms inside (100) plane. The friction coefficient COF on (100) is increased from 0.09 to 0.8 as the scratch load is added from 5 to $300 \mathrm{mN}$. This work is of great significance to provide the mechanical property of SnSe single crystal.
\end{abstract}

Key words: SnSe single crystal; vertical Bridgman method; mechanical property

During the past decades, thermoelectric (TE) material has attracted much attention as it can transfer heat directly into electricity and vice versa ${ }^{[1-3]}$. The conversion efficiency is evaluated by the dimensionless thermoelectric figure of merit $Z T=\left(S^{2} T \sigma\right) /\left(k_{\mathrm{tot}}\right)$, where $S$ is the Seebeck coefficient, $T$ is the absolute temperature, $\sigma$ is the electrical conductivity, and $k_{\text {tot }}$ is the total thermal conductivity $^{[4]}$. Therefore, the searching of TE material with excellent $Z T$ has become a significant target. In recent years, there is a $\mathrm{IV}-\mathrm{VI}$ SnSe single crystal has been investigated extensively due to its outstanding TE behavior and environment friendly charactistic. In 2014, Zhao, et $a l^{[5]}$ reported that the p-type SnSe single crystal showed an unprecedented $Z T$ of 2.6 along (100) plane due to the ultra-low thermal conductivity. From then on, the research of SnSe single crystal had become a hot point around the world, and high $Z T$ values were reported also in several groups ${ }^{[6-7]}$. And the n-type $\mathrm{SnSe}$ single crystals with $Z T$ values of 2.2 and 2.8 were also achieved by $\mathrm{PbBr}_{2}$ and $\mathrm{Bi}$ doping ${ }^{[8-9]}$. Therefore, it is no doubt that the breakthrough of SnSe single crystal opens up a bright future for TE application.

However, it should be pointed out that most of the present researches about $\mathrm{SnSe}$ single crystals are focused on its TE properties, other equally important information such as the mechanical performances are serious in shortage. It is imaginable that if $\mathrm{SnSe}$ single crystal is processed for TE module fabrication and then put into service, the material will inevitably experience complicated shocks and stress. Under this condition, the mechanical properties of SnSe single crystal would be essential to estimate whether it is proper for commercial application or not. According to publications, most of the work related to mechanical properties rely on SnSe polycrystalline, which usually prepared through hot pressing (HP) or spark plasma sintering (SPS) techniques ${ }^{[10-11]}$. Only a few study about SnSe single crystal is delivered up to now. For example, Zhao, et $a l^{[12]}$ revealed the lowest ideal strength of SnSe single crystal is $0.59 \mathrm{GPa}$ under the $(100) /<001>$ shear load by density functional theory calculation. In present work, we aim to investigate the mechanical behaviors of SnSe single crystal through micro-indentation and nanoscratch approaches. Pure SnSe single crystal is successfully grown via a vertical Bridgman method in the experiment, then, several mechanical parameters such as microhardness,

Received date: 2020-04-07; Revised date: 2020-06-07; Published online: 2020-07-21

Foundation item: Shanghai Natural Science Foundation (19ZR1419900)

Biography: JIN Min(1982-), male, professor. E-mail: jmaish@aliyun.com 金 敏(1982-)，男，教授.E-mail: jmaish@aliyun.com 
fracture toughness and friction constant on (100) are declared.

\section{Experimental}

\subsection{SnSe crystal growth}

99.999\% purity $\mathrm{Sn}$ and Se elements were used as raw materials for polycrystalline synthesis. They were weighted according to the standard stoichiometric ratio and the total weight was $98.6 \mathrm{~g}$. In order to prevent $\mathrm{SnSe}$ from oxidation once the utilized quartz ampoule was crack, an outside ampoule was simultaneously employed and they were all sealed with $\sim 10^{-2} \mathrm{~Pa}$ vacuum. Sn and Se reacted in a $900{ }^{\circ} \mathrm{C}$ rocking furnace which worked at a 20-25 r/min speed to enhance SnSe synthesis homogeneously. After that, SnSe single crystal growth was carried out in a homemade vertical Bridgman furnace. Fig. 1(a) shows the schematic diagram of the furnace, and the sealed quartz ampoule with SnSe polycrystalline was placed into the chamber and supported by a steel pillar. Fig. 1(b) exhibits the temperature profile of the furnace along vertical direction. The heating zone was about $200 \mathrm{~mm}$ in height, and the highest temperature was designed about $950{ }^{\circ} \mathrm{C}$. After $\mathrm{SnSe}$ polycrystalline was totally melted, SnSe crystal growth was executed through the lowing system at a $1.0 \mathrm{~mm} / \mathrm{h}$ rate, and the temperature gradient for crystallization was $10-15^{\circ} \mathrm{C} / \mathrm{cm}$. After all solution was exhausted, the furnace was cooled to room temperature naturally.

\subsection{Characterization}

The phase structure and crystal direction of $\mathrm{SnSe}$ crystal was analyzed by X-ray diffraction (Bruker D8, Germany) using $\mathrm{Cu} \mathrm{K \alpha}$ radiation $(\lambda=0.15406 \mathrm{~nm})$ at room temperature. The X-ray rocking curve of $\mathrm{SnSe}$ crystal was detected by D8 Discover (Bruker AXS, Germany). The configuration of crystal surface was examined by Energy Dispersive Spectrometer (Oxford Instruments, Britain), and the composition was tested by an EDAX system (Gemsis Software V 4.61). Vickers' microhardness equipment (Wilson-Wlpert Tukon 2100B) with a diamond square pyramid indentor was employed to induce indentations by keeping the indentor to the crystal surface for $10 \mathrm{~s}$ in all cases. The distance of indentations were enough far from each other so that the surface effects could be avoided. As for friction property evaluation, the nanoscratch tests were carried out via a Hysitron Triboindenter (MTS Systems Co., Oak Ridge, USA). A $90^{\circ}$ cono-spherical diamond tip was used for scratching, and the scratch speed was set as $0.5 \mu \mathrm{m} / \mathrm{s}$.

\section{Results and discussion}

Fig. 2(a) shows the as-grown SnSe crystal that is broken into parts by hand. It is noticed that the fracture surface display bright mirror gloss which is much similar to those of other SnSe single crystals prepared by vertical gradient frozen (VGF) and horizontal Bridgman (HB) methods ${ }^{[6-9]}$. Such crack behavior is contributed mainly by the special layer structure of $\mathrm{SnSe}$. In a single crystalline layer, each $\mathrm{Sn}(\mathrm{Se})$ atom connects to three neighboring $\mathrm{Se}(\mathrm{Sn})$ atoms though strong heteropolar bonds, however, the adjacent layers are weakly bonded with each other as the bonding between them is van der Waals forces ${ }^{[12]}$. As a result, SnSe single crystal is easy to cleave along the (100) plane $^{[5]}$. The SEM configuration in Fig. 2(b) shows this type of cleavage habit.

In Fig. 3(a), a $5 \mathrm{~mm} \times 10 \mathrm{~mm}$ SnSe wafer along $b c$ plane peels off from the crystal. XRD measurement indicates that the cleavage facet is precisely (100) as only (400) peak is detected in the range of $20^{\circ}-50^{\circ}$ diffraction angle. For comparison, the X-ray powder diffraction pattern of $\mathrm{SnSe}$ is also demonstrated. Obviously, all diffraction peaks are found matched well with the standard PDF\#48-1224 card, which means that the present SnSe single crystal has an expected orthorhombic Pnma space group at room temperature. However, it should be noted that the strongest peak in the XRD pattern is (400)
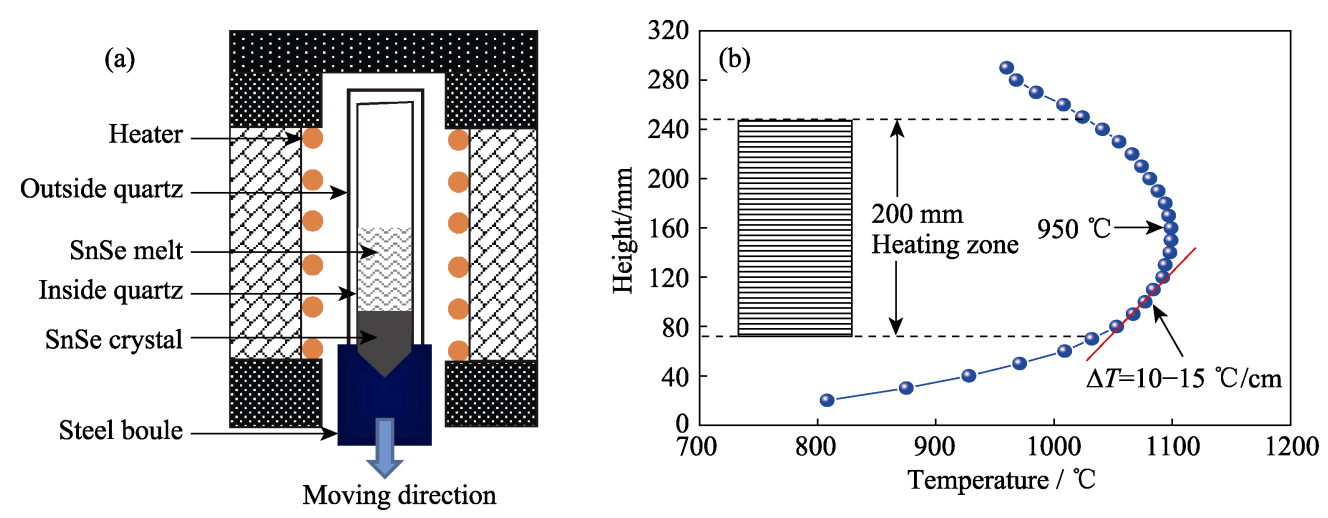

Fig. 1 Schematic diagram of vertical Bridgman furnace (a) and temperature profile along vertical direction (b) 

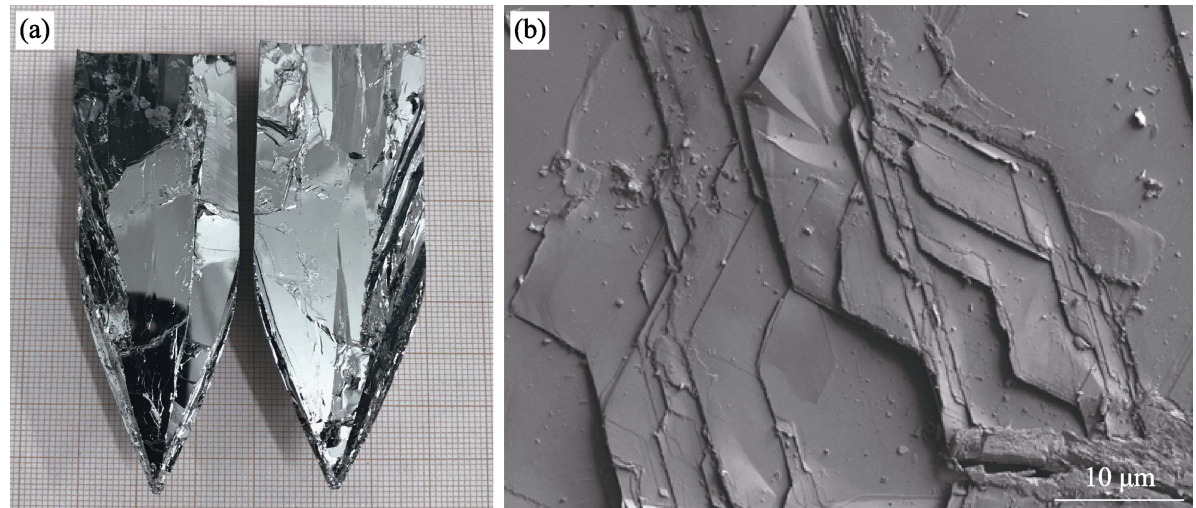

Fig. 2 As-grown SnSe crystal (a) and SEM morphology of the cleavage plane (b)
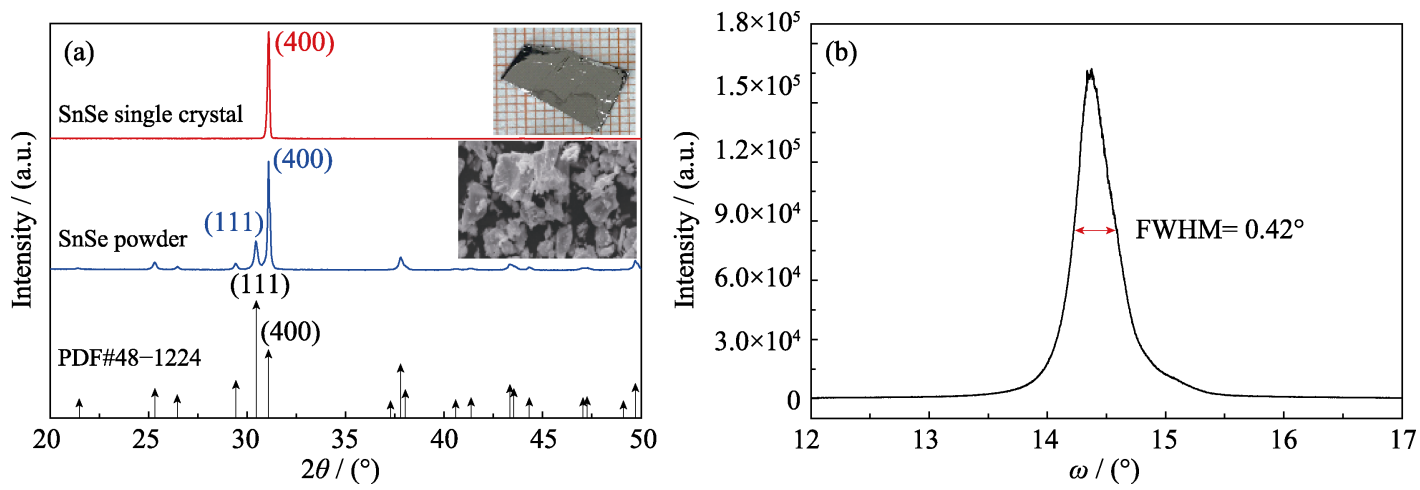

Fig. 3 XRD of (100) SnSe single crystal and powder (a) and X-ray rocking curve of (100) single crystal surface (b)

but not (111), which is inconsistent with the standard map. This result can be explained as SnSe powder is apt to possess (400) orientation when the crystal is ground due to its great cleavage inertia. Based on the XRD data, the crystal lattice parameters $a, b$ and $c$ are calculated to be $1.1493,0.4156$ and $0.4441 \mathrm{~nm}$, respectively, by a general structure analysis system, which match well with the previous result ${ }^{[13]}$. Fig. 3(b) shows the X-ray rocking curve of (100) SnSe single crystal, which indicates the full width at half maximum (FWHM) is $\sim 0.42^{\circ}$. In order to clarify the chemical composition of $\mathrm{SnSe}$, EDS analysis is carried out. The mole ratio of $\mathrm{Sn}$ to $\mathrm{Se}$ is detected nearly $0.99: 1$ that is slight deviated from standard stoichiometric ratio, as shown in Fig. 4(a).

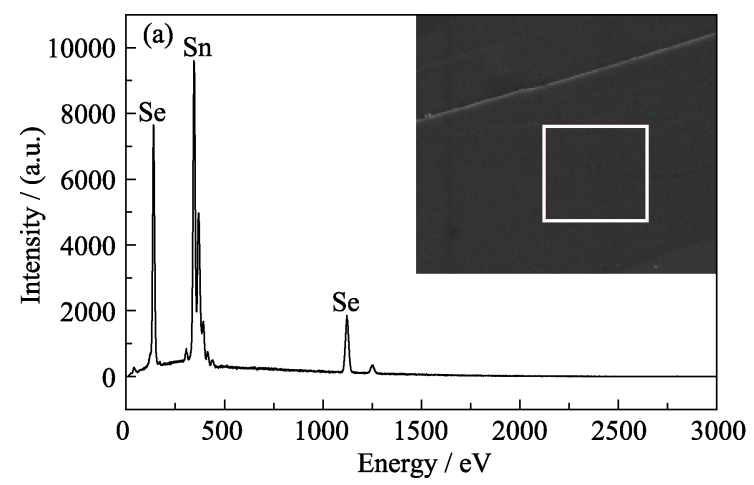

Fig. 4(b) displays the linear EDS map of elements, it is observed that both $\mathrm{Sn}$ and $\mathrm{Se}$ are homogeneously distributed in a $80 \mu \mathrm{m}$ scanning length.

Fig. 5(a) shows the schematic diagram of microindentation for mechanical properties evaluation, where $d_{1}\left(d_{2}\right)$ and $2 c_{1}\left(2 c_{2}\right)$ represent the length of indentation diagonals and cracks, respectively. Vickers microhardness $\mathrm{HV}$ is an important parameter, describing the ability of blocking hard objects. it is usually calculated according to the following formula ${ }^{[14]}$ :

$$
\mathrm{HV}=1.8544 \frac{P}{d^{2}}
$$

Where $P$ is the applied load in kilogram, $d$ is the average indentation diagonal length in micrometers measured

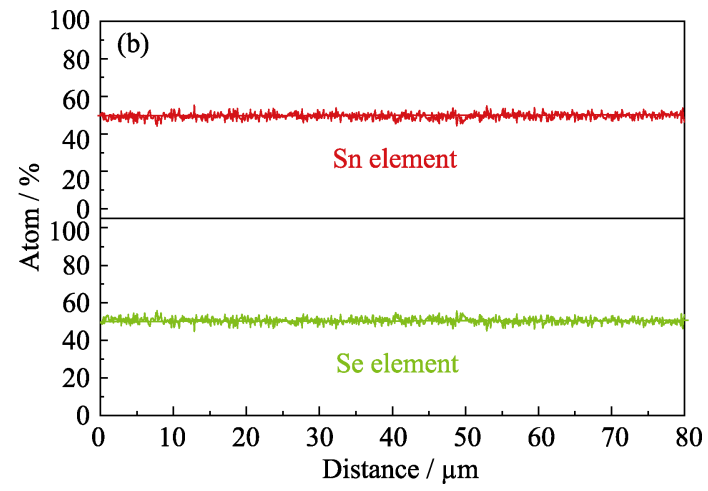

Fig. 4 Composition analysis on (100) plane of SnSe single crystal (a) and linear EDS map of Sn/Se elements (b) 
through a filar micrometer eyepiece. In the experiment, three loads $(P=0.01,0.025$ and $0.05 \mathrm{~kg})$ are adopted for testing. The relationship of $d$ and $\mathrm{HV}$ with $P$ display in Fig. 5(b). It is found that $d$ linearly increases from 19.07 to $41.24 \mu \mathrm{m}$ as $P$ is added. However, the corresponding $\mathrm{HV}$ varies slightly with the average value of about $53 \mathrm{MPa}$. This HV is on the same level compared to that of $\mathrm{Sn}_{0.985} \mathrm{Na}_{0.015} \mathrm{Se}$ polycrystalline $(69.6 \mathrm{MPa})$ fabricated by SPS, but is much lower than those of $\mathrm{Bi}_{2} \mathrm{Te}_{3}$-based, PbTe-based and half-Heusler alloys ${ }^{[15-18]}$, which means SnSe single crystal is a very soft material.

Fracture toughness $K_{\mathrm{c}}$ is another significant parameter to estimate the resistance to cracking. The calculation of $K_{\mathrm{c}}$ depends on the ratio of $c / a^{[14]}$ :

$$
\begin{gathered}
K_{\mathrm{c}}=(k P / c)^{3 / 2} \quad c / a>2.5 \\
K_{\mathrm{c}}=k(P / a l)^{1 / 2} \quad c / a \leqslant 2.5
\end{gathered}
$$

Where $a$ is half of diagonal length, $l=c-a$ is the mean crack length, the constant $k$ is $1 / 7$ for Vickers indenter. The insert picture in Fig. 5(b) illustrates an indentation pressed by $0.05 \mathrm{~kg}$ load. It is noticed that little or no cracks are taken place from the diagonal points, such phenomenon means that the crack length $l$ is nearly zero and $K_{\mathrm{c}}$ is infinity. Besides, it should be paid attention that the crystal surface around indention is sunken or arched up, which is seldom observed in other brittle materials ${ }^{[19-21]}$. These results declare that SnSe single crystal has wonderful fracture toughness which mainly benefits from the strong heteropolar bonds between $\mathrm{Sn}$ and $\mathrm{Se}$ atoms inside (100) plane.

Fig. 6(a) displays the relationship of friction coefficient COF with scratch time by $5 \mathrm{mN}$ scratch load. It is observed that COF is frequently waved around an average value $\sim 0.09$. Fig. $6(\mathrm{~b})$ is the dependence of horizontal force $F_{\mathrm{z}}$ on scratch time. $F_{\mathrm{z}}$ demonstrates regular change and the periodic time is about $0.67 \mathrm{~s}$. As the applied load is added to $100 \mathrm{mN}$, COF varies intensely along with scratch time in Fig. 6(c). This phenomenon is mainly attributed to the deeper pressing depth of nanoindenter on crystal surface after the load is increased. As nanoindenter keeps moving forward, multi-layer SnSe sheets are lifted up due to the weak van der Waals force between SnSe layers, as a result, the oscillation of friction coefficient is happened. The average COF value under $100 \mathrm{mN}$ load is $\sim 0.35$, which is almost four times as high as that under $5 \mathrm{mN}$ load. Fig. 6(d) is the corresponding relationship of $F_{\mathrm{z}}$ with scratch time. It shows that $F_{\mathrm{z}}$ randomly fluctuats in the course of nanoindenter moving, verifying the irregular variation of COF under $100 \mathrm{mN}$ load.

Furthermore, as the applied load is increased to $300 \mathrm{mN}$, the change of COF with scratch time becomes much regular in Fig. 6(e). COF value changes from peak (trough) to trough (peak) in every $2.5 \mathrm{~s}$, and the average COF is near 0.8 (the highest and lowest COF is 1.2 and 0.4 , respectively). Fig. 6(f) shows the dependence of $F_{\mathrm{z}}$ on scratch time, it is found that $F_{\mathrm{z}}$ would reach a lowest value during a period time which matches well with the change of COF. This phenomenon is mainly due to the special adhesion-slip motion of nanoindenter on (100) SnSe surface. At the beginning, nanoindenter is pressed into the crystal. Then, as nanoindenter is scratched, the movement of nanoindenter would be opposed remarkably by the plastic deformation of $\mathrm{SnSe}$ and protruding portions of the material in front of nanoindenter. As a result, the $F_{\mathrm{z}}$ value increases gradually. When $F_{\mathrm{z}}$ is accumulated to a certain extent, crystal slip will induce COF to decrease sharply. After that, the above process will circularly happens with the $\mathrm{COF} / F_{\mathrm{z}}$ curves periodic ally changed.

In order to better understand the friction performance of (100) SnSe crystal, a ramping load mode is also introduced. Fig. 7 shows the data that measured under $0-300 \mathrm{mN}$ load within $30 \mathrm{~s}$. It is noticed that as the load is evenly increased, the indentation depth is linearly added, and the final depth reaches $0.18 \mathrm{~mm}$. As for COF, three stages could be divided from the shape of diagram. Firstly, COF is kept on a low level in early $7.5 \mathrm{~s}$ which
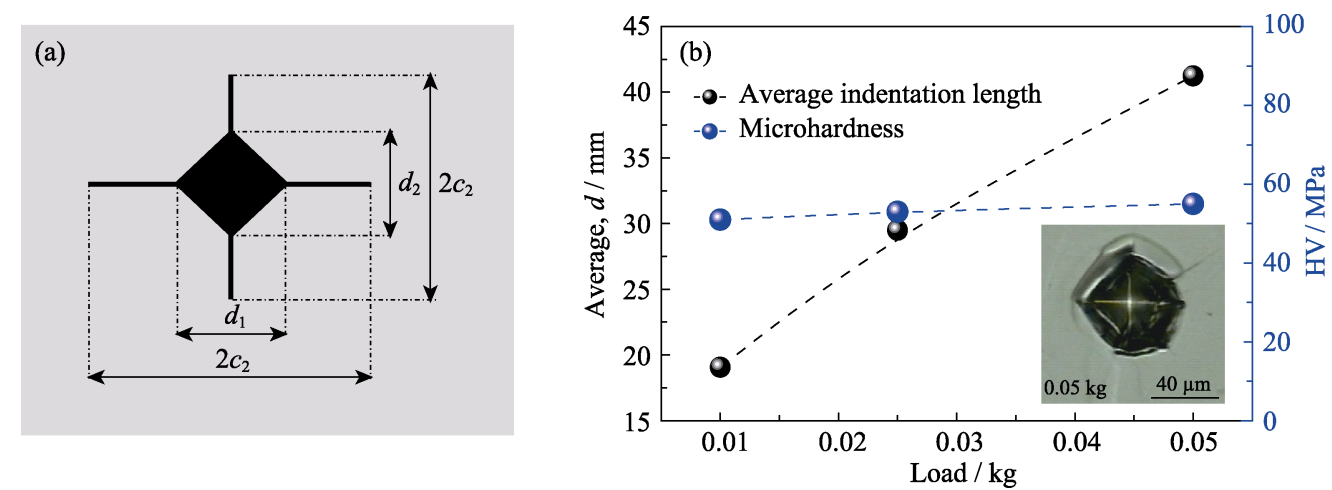

Fig. 5 Schematic diagram of microindentation (a), dependence of average indentation diagonal length $d$ and microhardness HV on applied load (b) 

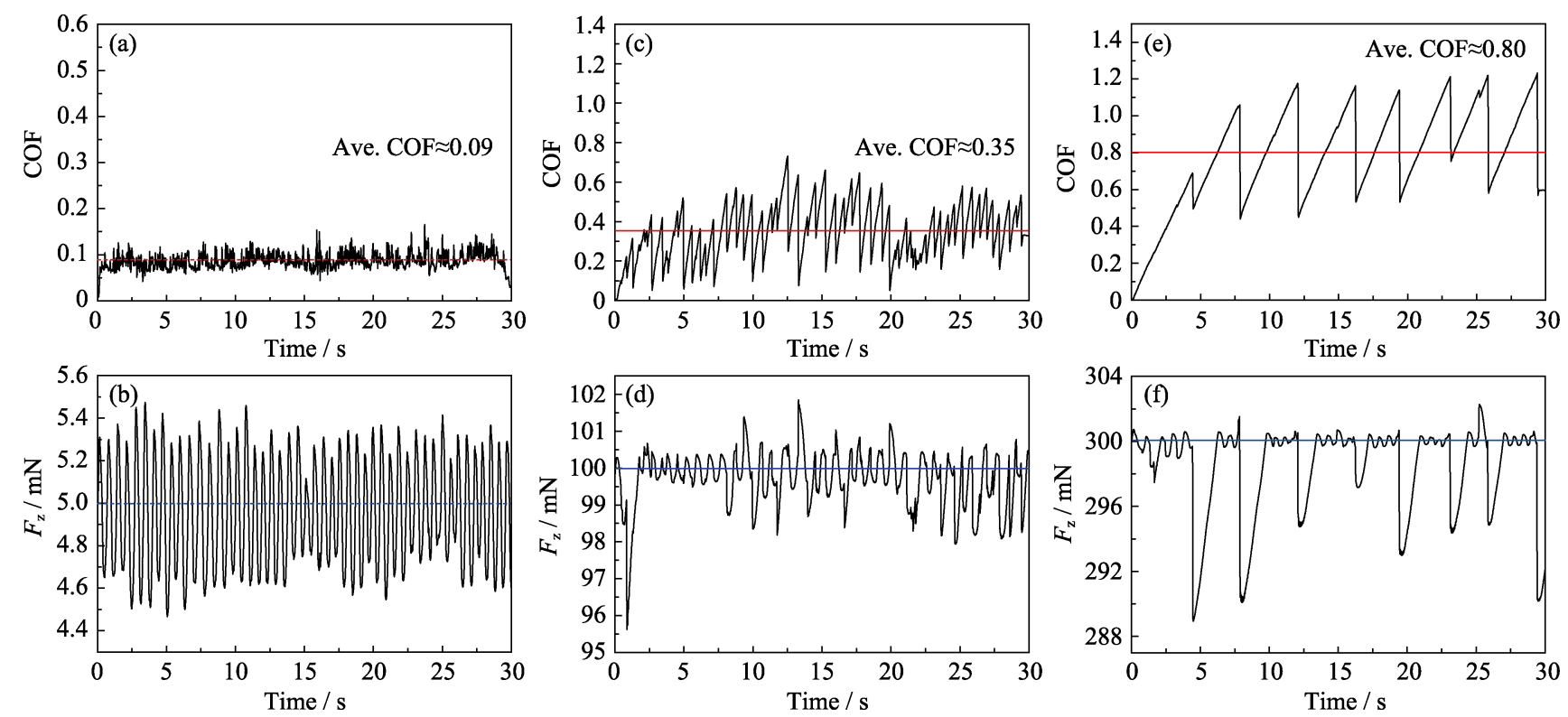

Fig. 6 Relationship of friction coefficient COF and horizontal force $F_{\mathrm{z}}$ with scratch time under $5 \mathrm{mN}(\mathrm{a}-\mathrm{b})$, $100 \mathrm{mN}(\mathrm{c}-\mathrm{d})$ and $300 \mathrm{mN}(\mathrm{e}-\mathrm{f})$ applied load

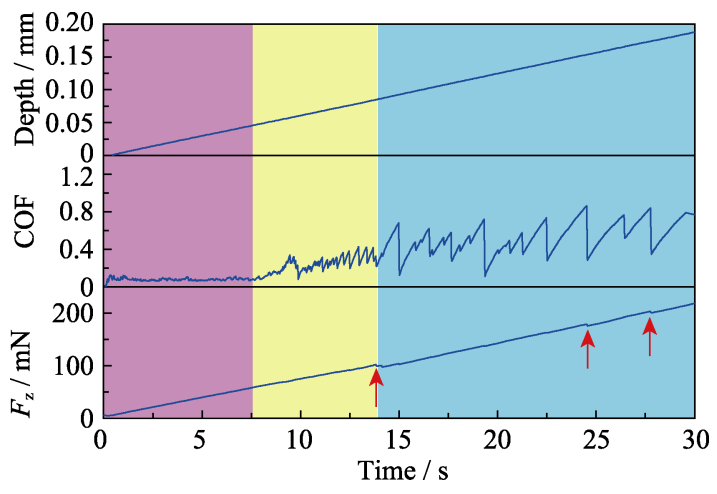

Fig. 7 Relationship of nano-indentation depth, friction coefficient $\mathrm{COF}$ and horizontal force $F_{\mathrm{z}}$ with ramping load from 0 to $300 \mathrm{mN}$

means that the crystal surface is much smooth under small load. This phenomena is in consistent with the result as Fig. 6(a) illustrates. Secondly, in range of 7.5-13.5 s time, the applied load is increased from $75 \mathrm{mN}$ to $135 \mathrm{mN}$. During this stage, the COF variation follows the trend as Fig. 6(c) described. Finally, as the applied load is further raised, COF starts to change periodically. These COF variation rules repeatedly declare the different friction mechanisms as exhibited above. As for $F_{\mathrm{z}}$, the value is almost linearly increased, however, several tortuous points might attribute to the slight press fluctuation of nanoindentation on (100) SnSe single crystal surface.

\section{Conclusions}

SnSe single crystal is an attractive thermoelectric material. The as-grown SnSe crystal has standard orthorhombic Pnma space group at room temperature by vertical
Bridgman method. The average Vickers microhardness $H_{\mathrm{v}}$ is measured to be only $53 \mathrm{MPa}$ under $0.01-0.05 \mathrm{~kg}$ load, which implies SnSe single crystal is a very soft material. Nevertheless, it exhibits excellent fracture toughness as none crack is propagated from the indentation diagonal points. The friction coefficient COF on (100) is measured as $0.09,0.35$ and 0.8 under 5,100 and $300 \mathrm{mN}$ scratch loads, respectively.

\section{References:}

[1] BISWAS K, HE J Q, BLUM I D, et al. High-performance bulk thermoelectrics with all-scale hierarchical architectures. Nature, 2012, 489(7416): 414-418.

[2] DISALVO F J. Thermoelectric cooling and power generation. Science, 1999, 285(5428): 703-706.

[3] SNYDER G J, TOBERER E S. Complex thermoelectric materials. Nature Materials, 2008, 7(2): 105-114.

[4] TRIPATHI M N, BHANDARI C M. High-temperature thermoelectric performance of $\mathrm{Si}-\mathrm{Ge}$ alloys. Journal of PhysicsCondensed Matter, 2003, 15(31): 5359.

[5] ZHAO L D, LO S H, ZHANG Y, et al. Ultralow thermal conductivity and high thermoelectric figure of merit in SnSe crystals. Nature, 2014, 508(7496): 373-377.

[6] ZHAO L D, TAN G, HAO S, et al. Ultrahigh power factor and thermoelectric performance in hole-doped single-crystal SnSe. Science, 2015, 351(6269): 141.

[7] PENG K L, HUI S, ZHOU X Y, et al. Broad temperature plateau for high $Z T \mathrm{~s}$ in heavily doped p-type SnSe single crystals. Energy \& Environmental Science, 2016, 9(2): 454-460.

[8] CHANG C, WU M, HE D, et al. 3D charge and 2D phonon transports leading to high out-of-plane $Z T$ in n-type SnSe crystals. Science, 2018, 360: 778-783.

[9] DUONG A T, NGUYEN V Q, DUVJIR G, et al. Achieving $Z T=2.2$ with Bi-doped n-type SnSe single crystals. Nature Communications, 2016, 7: 13713. 
[10] LI G D, AYDEMIR U, WOOD M, et al. Ideal strength and deformation mechanism in high-efficiency thermoelectric SnSe. Chemistry of Materials, 2017, 29: 2382-2389.

[11] FU J, SU X, XIE H, et al. Understanding the combustion process for the synthesis of mechanically robust SnSe thermoelectrics. Nano Energy, 2018, 44: 53-62.

[12] CHEN Z G, SHI X L, ZHAO L D, et al. High-performance SnSe thermoelectric materials: progress and future challenge. Progress in Materials Science, 2018, 97: 283-346.

[13] WU D, WU L J, ZHAO L D, et al. Direct observation of vast off-stoichiometric defects in single crystalline SnSe. Nano Energy, 2017, 35: 321-330.

[14] JIN M, XU J Y, LI X H, et al. Microhardness and fracture toughness of $<111>$ oriented PZNT single crystal. Materials Science and Engineering A, 2008, 472(1): 353-357.

[15] CHU F, ZHANG Q, ZHOU Z, et al. Enhanced thermoelectric and mechanical properties of Na-doped polycrystalline SnSe thermoelectric materials via CNTs dispersion. J. Alloys Compd., 2018, 741: $756-764$.
[16] XU Z J, HU L P, YING P J, et al. Enhanced thermoelectric and mechanical properties of zone melted p-type $\left(\mathrm{Bi}, \mathrm{Sb}_{2} \mathrm{Te}_{3}\right.$ thermoelectric materials by hot deformation. Acta Materialia, 2015, 84: 385-392.

[17] REN F, HALL B D, NI J E, et al. Mechanical Characterization of $\mathrm{PbTe}$-based Thermoelectric Materials. Materials Research Society Symposium Proceedings, 2008, 1044: 121.

[18] LIU Z, GAO W, MENG X, et al. Mechanical properties of nanostructured thermoelectric materials $\alpha-\mathrm{MgAgSb}$. Scripta Materialia, 2017, 127: 72-75.

[19] JIN M, XU J Y, SHI M L, et al. Mechanical properties anisotropy of PZNT93/7 single crystal. Journal of Physics D: Applied Physics, 2007, 40(5): 1473-1476.

[20] JIN M, FANG Y Z, SHEN H, et al. Mechanical property evaluation of GaAs crystal for solar cells. Chinese Physics Letters, 2011, 28(8): 086101.

[21] GUPTA V, BAMZAI K K, KOTRU P N, et al. Mechanical characteristics of flux-grown calcium titanate and nickel titanate crystals. Materials Chemistry \& Physics, 2005, 89: 64-71.

\title{
坩埚下降法生长 SnSe 单晶及其力学性能研究
}

\author{
金 敏 ${ }^{1}$ ，白旭东 ${ }^{1,2}$, 赵 素 ${ }^{1}$, 张如林 ${ }^{1}$, 陈玉奇 ${ }^{1}$, 周丽娜 ${ }^{1}$
}

(1. 上海电机学院 材料学院, 上海 201306; 2. 上海理工大学 材料科学与工程学院, 上海 200093)

摘 要: IV-VI SnSe 单晶是一种引人注目的热电材料, 不仅热电性能优异而且还具有环境友好的特征。本工作探索了 一种制备 SnSe 单晶的技术, 并对产品的力学性能进行研究。利用坩埚下降法成功生长了化学计量比准确的非掺杂 SnSe 单晶, 其在室温下具有标准 Pnma 正交相结构。由于 $\mathrm{Sn}$ 层与 Se 层之间的结合力非常弱, SnSe 单晶很容易沿(100) 面解理。显微压痕测试表明 $\mathrm{SnSe}$ 单晶十分柔软, 0.01 0.05 kg 载荷下的平均显微维氏硬度 $\mathrm{HV}$ 仅为 $53 \mathrm{MPa}$ 。然而, 得 益于层内 $\mathrm{Sn}$ 和 $\mathrm{Se}$ 原子之间强烈的极性耦合, $\mathrm{SnSe}$ 单晶沿(100)面却展现出了优异的断裂韧性。纳米划痕实验显示 $\mathrm{SnSe}$ 单晶(100)面在 5 300 $\mathrm{mN}$ 划痕压力范围内的摩擦系数 $\mathrm{COF}$ 可从 0.09 增加到 0.8 。本工作对完善 $\mathrm{SnSe}$ 单晶的力学性能 信息具有重要意义。

关 键 词: $\mathrm{SnSe}$ 单晶; 坩埚下降法; 力学性能

中图分类号: TQ174 文献标识码: A 